\title{
Cytomegalovirus remains viable in naturally infected breast milk despite being frozen for 10 days
}

\author{
N Curtis, L Chau, S Garland, S Tabrizi, R Alexander, C J Morley
}

Arch Dis Child Fetal Neonatal Ed 2005;90:F529-F530. doi: 10.1136/adc.2004.067769

Cytomegalovirus culture positive breast milk was obtained from four mothers of very premature babies. The milk was stored at $0-5^{\circ} \mathrm{C}$ in a domestic refrigerator for 48 hours or frozen for different durations at $-20^{\circ} \mathrm{C}$. Cytomegalovirus survived in breast milk despite being frozen for 10 days at $-20^{\circ} \mathrm{C}$.

\footnotetext{
C
} ytomegalovirus (CMV) re-activation and shedding in breast milk is common during the postnatal period, and the virus is often transmitted to the baby. ${ }^{1}$ Although CMV infection usually presents no threat to term infants, its clinical consequence in very premature babies is still uncertain. ${ }^{2}$ The efficacy of freezing naturally infected breast milk to eliminate CMV is also uncertain. ${ }^{3}$ This study aimed to investigate the freezing duration required to eliminate viable CMV from breast milk and whether baseline CMV viral load affects the effectiveness of freezing.

\section{METHODS}

Subjects and milk storage

CMV culture positive breast milk was obtained from four mothers of very premature babies at the Royal Women's Hospital, Melbourne, Australia after informed consent. The milk was divided into multiple $3 \mathrm{ml}$ aliquots for culture before or after storage at $0-5^{\circ} \mathrm{C}$ in a domestic refrigerator for 48 hours or freezing for different durations at $-20^{\circ} \mathrm{C}$.

\section{CMV culture}

After thawing at $37^{\circ} \mathrm{C}$ in an incubator, milk samples were defatted and separated into cellular and aqueous (whey) fractions by centrifugation. CMV culture was undertaken on each fraction separately using the highly sensitive rapid enhanced tissue culture immunofluorescence (RETCIF) method. ${ }^{4}$ Briefly, fractions were diluted, vortexed, sonicated, and centrifuged. Supernatant (200-300 $\mu \mathrm{l})$ from the cellular and aqueous fractions was inoculated separately into tissue culture plates. After further centrifugation, supernatant from each well was replaced by viral maintenance medium. After incubation at $37^{\circ} \mathrm{C}$ for two days, the cultures were tested for the presence of CMV by direct immunofluorescence using monoclonal antibodies. Negative samples were tested again after 10 days incubation.

\section{Quantification of baseline CMV viral load}

A $200 \mu \mathrm{l}$ aliquot of stored $\left(-70^{\circ} \mathrm{C}\right)$ milk from baseline was thawed and centrifuged. DNA from the cellular and supernatant (whey) fractions was prepared using an automated MagNA Pure LC (Roche Diagnostics, Indianapolis, Indiana, USA) with the associated DNA Isolation Kit I protocol. Quantification was by real time polymerase chain reaction using a Lightcycler (Roche Diagnostics). Primers (gBfor and
gBrev) targeted to a 254 bp region on the glycoprotein B gene were used with hybridization probes labelled with fluorescein or LC-Red 640 for a nested region within the amplification area. CMV was quantified by comparison of amplification crossing points from five 10 -fold serial dilutions of a plasmid standard containing the primer spanning region of the glycoprotein B gene to the samples. The presence of adequate amplifiable DNA in each sample was assessed by separately amplifying a $260 \mathrm{bp}$ product of the human $\beta$ globin gene using GH20 and PCO4 primers.

\section{RESULTS}

Table 1 details the results. Initial CMV viral load in the seven samples tested varied between 1.8 and 110.1 copies/ $\mu$ l. CMV was cultured from all the samples after freezing for 24 hours and in five of seven (72\%) after freezing for 48 hours. In the three samples tested after longer freezing, viable CMV was still detected after 10 days. CMV was undetectable after freezing for 20 days in the two samples tested. Baseline viral load of CMV was lower in samples in which CMV was undetectable after freezing for 48 hours, than those that tested positive. After refrigeration for 48 hours, CMV was undetectable in three of the seven $(43 \%)$ samples.

\section{DISCUSSION}

Concerns about CMV transmission to very premature babies have led to the suggestion that breast milk from CMV seropositive mothers should be routinely frozen at $-20^{\circ} \mathrm{C} .{ }^{5}$ Our study is the first to show the persistence of viable CMV in naturally infected breast milk after being frozen for 10 days at $-20^{\circ} \mathrm{C}$. This finding is consistent with the recently published study by Hamprecht et al that showed infectivity of breast milk artificially spiked with CMV despite 10 days of freezing at $-20^{\circ} \mathrm{C}$. Of note, in our study, CMV persistence was found in samples of variable initial viral load, including as few as 10.9 copies/ $\mu \mathrm{l}$, a factor of at least 50 times lower than the concentrations tested in Hamprecht's spiking experiments.

The RETCIF culture method for CMV is highly sensitive. ${ }^{4}$ The relation between detection of CMV using a sensitive culture technique and infectivity of breast milk remains unknown, and the clinical significance of our findings is therefore uncertain. Only further prospective clinical studies can determine the importance of CMV transmission from breast milk to very premature babies and whether this has a significant impact on babies' clinical status and outcome. In the meantime, our study shows that routine freezing may not eliminate CMV from breast milk from mothers of very premature babies.

Abbreviations: CMV, cytomegalovirus; RETCIF, rapid enhanced tissue culture immunofluorescence 
Table 1 Results of cytomegalovirus (CMV) testing of frozen and refrigerated breast milk

\begin{tabular}{|c|c|c|c|c|c|c|c|c|c|c|c|c|c|}
\hline \multicolumn{3}{|c|}{ Mother } & \multicolumn{2}{|l|}{ Baby } & \multicolumn{2}{|l|}{ Milk } & \multirow{2}{*}{$\begin{array}{l}\text { Refrig } \\
48 \mathrm{~h}\end{array}$} & \multicolumn{6}{|c|}{ Duration of freezing } \\
\hline No & $\begin{array}{l}\text { Age } \\
\text { (years) }\end{array}$ & Parity & $\begin{array}{l}\text { Gest } \\
\text { (weeks) }\end{array}$ & $\begin{array}{l}\text { BW } \\
\text { (g) }\end{array}$ & Day & VL & & $24 \mathrm{~h}$ & $48 \mathrm{~h}$ & 5 days & 7 days & 10 days & 20 days \\
\hline 1 & 19 & 1 & 25 & 754 & $\begin{array}{l}8 \\
21 \\
31 \\
43\end{array}$ & $\begin{array}{l}1.8 \\
7.1 \\
10.1 \\
13.5\end{array}$ & $\begin{array}{l}-- \\
++ \\
++ \\
++\end{array}$ & $\begin{array}{l}++ \\
++ \\
++ \\
++\end{array}$ & $\begin{array}{l}-- \\
-- \\
++ \\
++\end{array}$ & ++ & & & \\
\hline 2 & 24 & 1 & 25 & 604 & 71 & 11.0 & ++ & ++ & ++ & ++ & ++ & ++ & \\
\hline 3 & 37 & 3 & 28 & 890 & 47 & 110.1 & -- & ++ & ++ & ++ & + & ++ & -- \\
\hline 4 & 25 & 1 & 26 & 665 & 19 & 10.9 & -- & ++ & +- & ++ & +- & ++ & -- \\
\hline
\end{tabular}

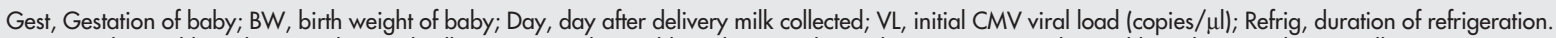
,++ CMV detected by culture in whey and cells; +-, CMV detected by culture in whey only; - -, CMV not detected by culture in whey or cells.

\section{What is already known on this topic}

- CMV re-activation and shedding in breast milk is common during the postnatal period and the virus is often transmitted to babies

- The clinical consequence of CMV infection by this route in very premature babies is uncertain

\section{What this study adds}

- Freezing breast milk from mothers of very premature babies for up to 10 days does not eliminate viable CMV

- This study underlines the importance of further prospective clinical studies to determine whether CMV transmission from breast milk to very premature babies has a significant impact on clinical status and outcome

\section{Authors' affiliations}

N Curtis, Paediatric Infectious Diseases Unit, Department of General Medicine, Royal Children's Hospital, Melbourne, Australia

N Curtis, L Chau, C J Morley, Department of Paediatrics, University of Melbourne, Royal Children's Hospital, Melbourne, Australia
N Curtis, C J Morley, Murdoch Children's Research Institute, Melbourne, Australia

S Garland, S Tabrizi, Department of Clinical Microbiology and Infectious Diseases, Royal Women's \& Royal Children's Hospitals, Melbourne, Australia

S Garland, S Tabrizi, Department of Obstetrics and Gynaecology, University of Melbourne, Royal Women's Hospital, Melbourne, Australia R Alexander, Virology Laboratory, Department of Microbiology and Infectious Diseases, Royal Children's Hospital, Melbourne, Australia C J Morley, Department of Neonatal Medicine, Royal Women's and Royal Children's Hospitals, Melbourne, Australia

Competing interests: none declared

Correspondence to: Associate Professor Curtis, Department of Paediatrics, University of Melbourne, Royal Children's Hospital, Parkville, VIC 3052, Australia; nigel.curtis@rch.org.au

Accepted 11 February 2005

\section{REFERENCES}

1 Hamprecht K, Maschmann J, Vochem M, et al. Epidemiology of transmission of cytomegalovirus from mother to preterm infant by breastfeeding. Lancet 2001;357:513-18.

2 Bryant P, Morley C, Garland S, et al. Cytomegalovirus transmission from breast milk in premature babies: does it matter? Arch Dis Child Fetal Neonatal Ed 2002;87:F75-7.

3 Hamprecht K, Maschmann J, Muller D, et al. Cytomegalovirus (CMV) inactivation in breast milk: reassessment of pasteurization and freeze-thawing. Pediatr Res 2004;56:529-35.

4 Alexander R, Lamb D, White D, et al. 'RETCIF': a rapid, sensitive method for detection of viruses, applicable for large numbers of clinical samples. J Virol Methods 2001;97(1-2):77-85.

5 Sharland M, Khare M, Bedford-Russell A. Prevention of postnatal cytomegalovirus infection in preterm infants. Arch Dis Child Fetal Neonatal Ed 2002;86:F140. 